\title{
CHARACTERIZATION OF PHASE STRUCTURES OF NOVEL METALLO-POLYURETHANES
}

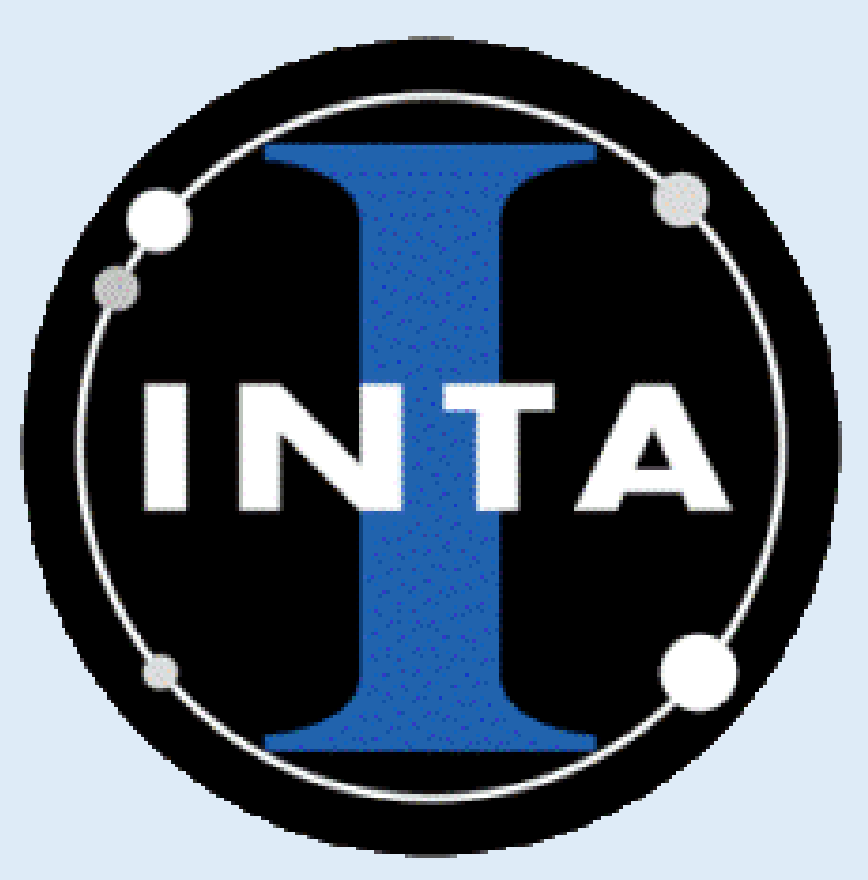

\author{
Beatriz Lucio $^{1}$, María Luisa Cerrada ${ }^{2}$ and José Luis de la Fuente ${ }^{1}$ \\ 'Instituto Nacional de Técnica Aeroespacial "Esteban Terradas" (INTA) \\ Ctra. de Ajalvir, Km. 4, Torrejón de Ardoz, Madrid, 28850 \\ 2 Instituto de Ciencia y Tecnología de Polímeros (ICTP). Consejo Superior de Investigaciones Científicas (CSIC) \\ C/ Juan de la Cierva 3, Madrid, 28006
}

luciocb@inta.es,mlcerrada@ictp.csic.es, fuentegj@inta.es

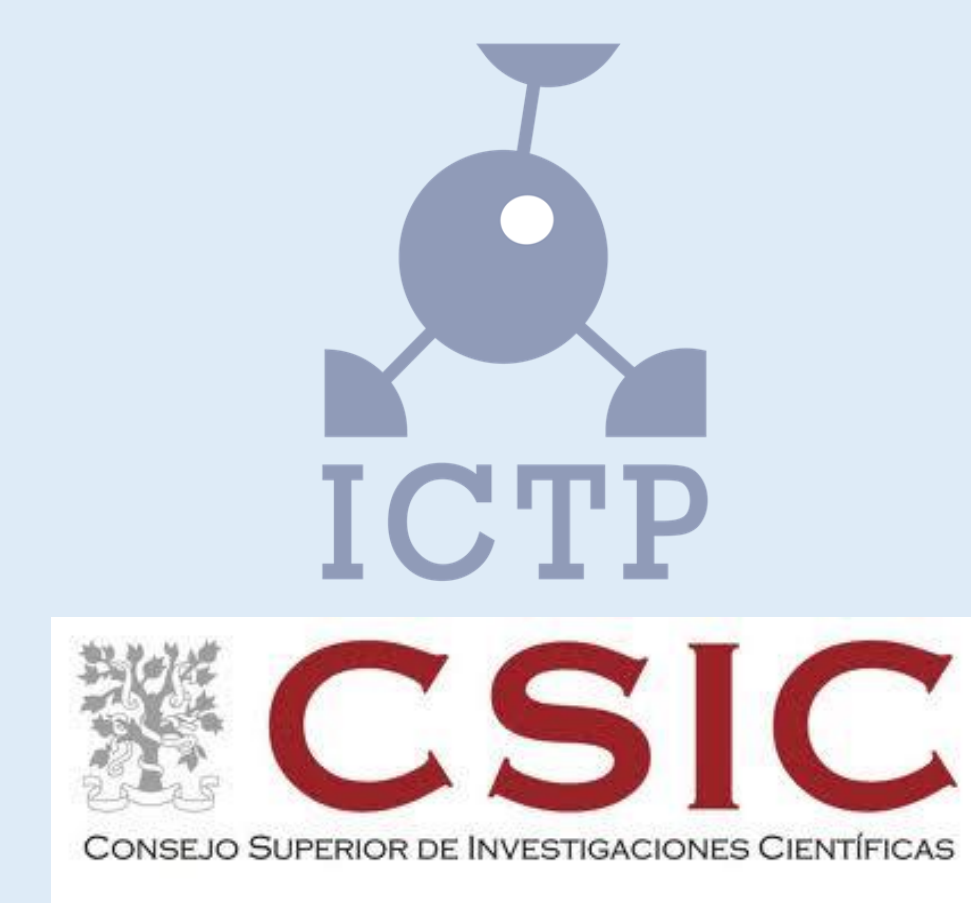

Abstract

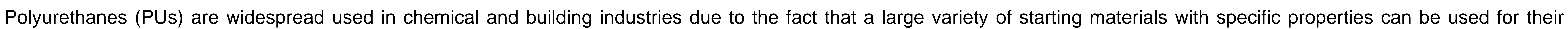

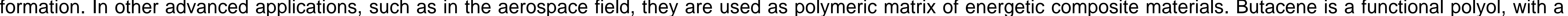

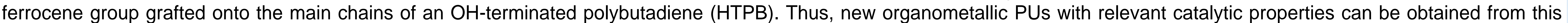
prepolymer.

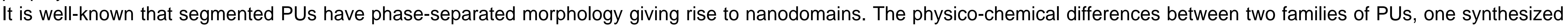

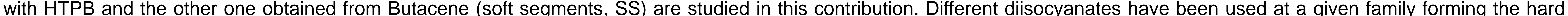

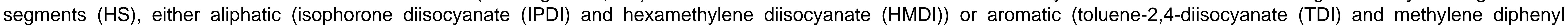

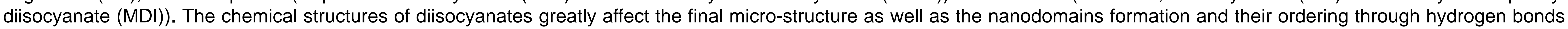

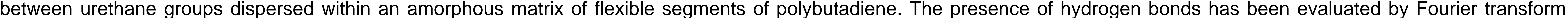

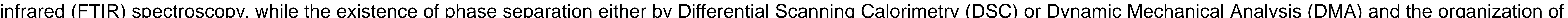
those domains by X-ray diffraction.

\section{Materials}

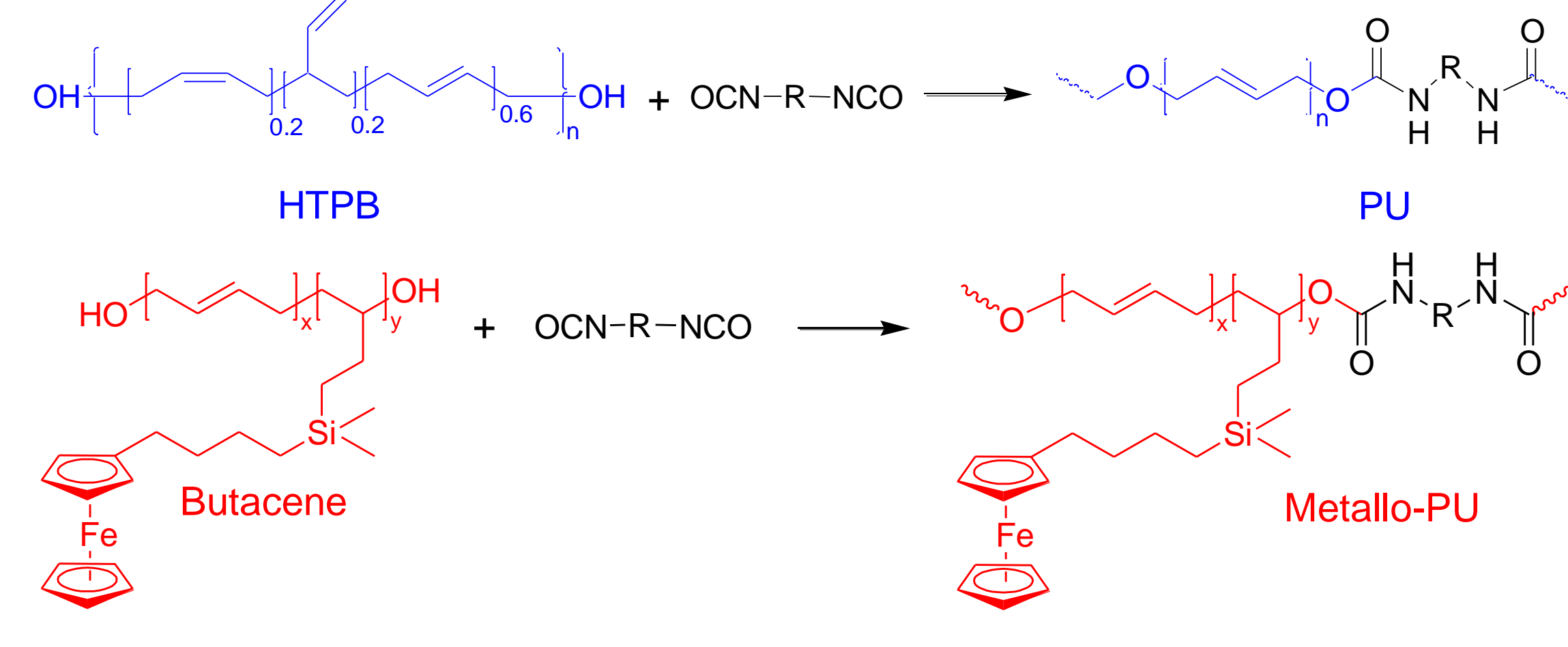

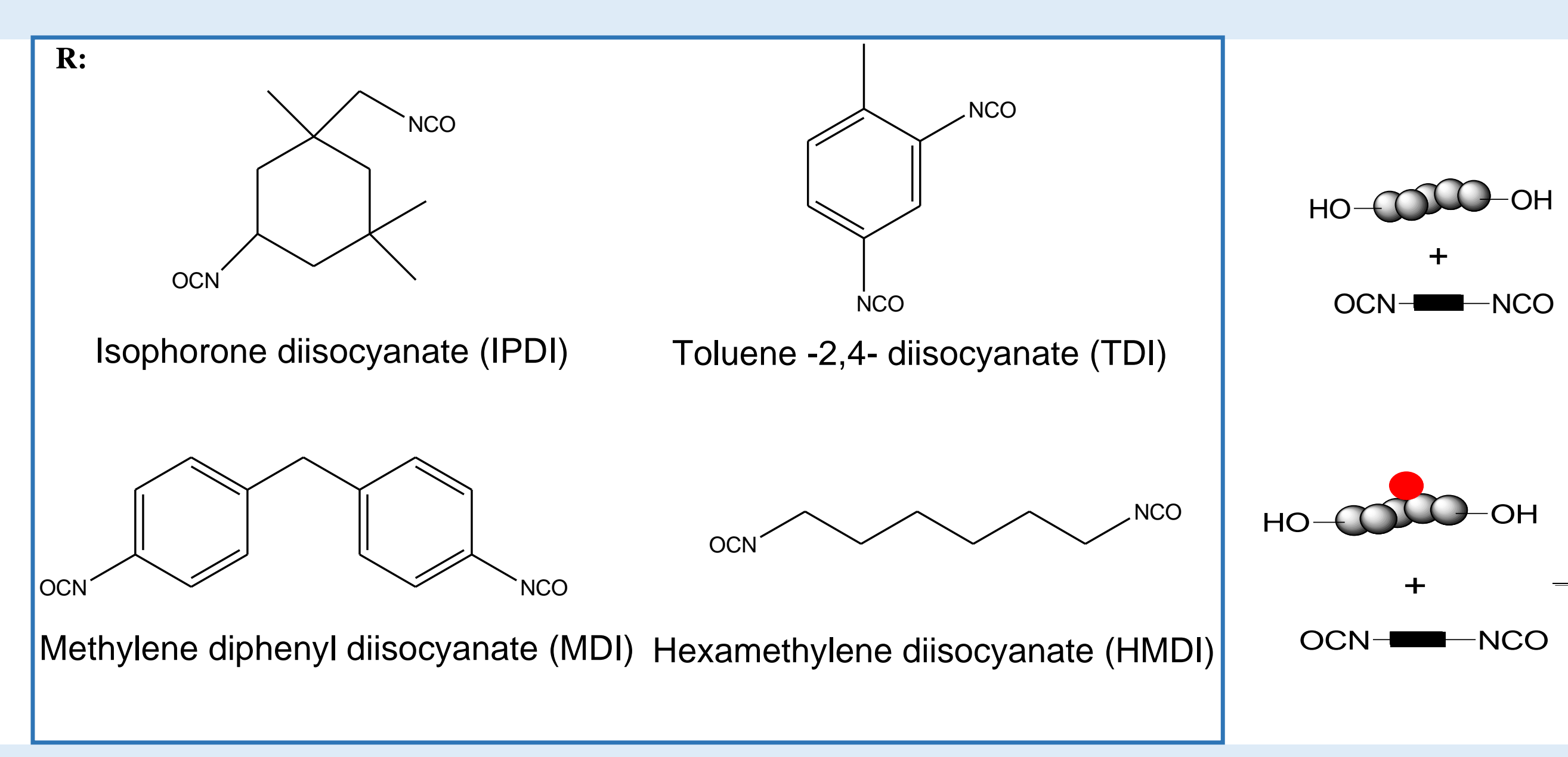
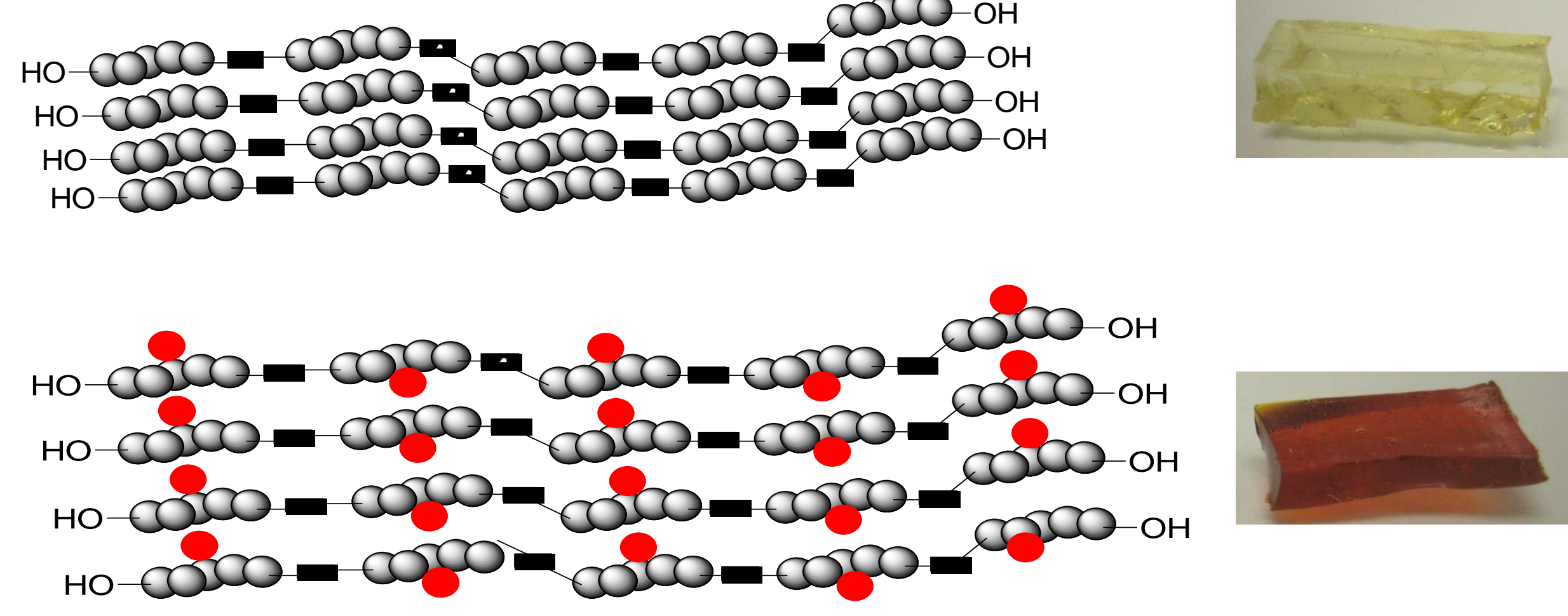

\section{Results and discussion}

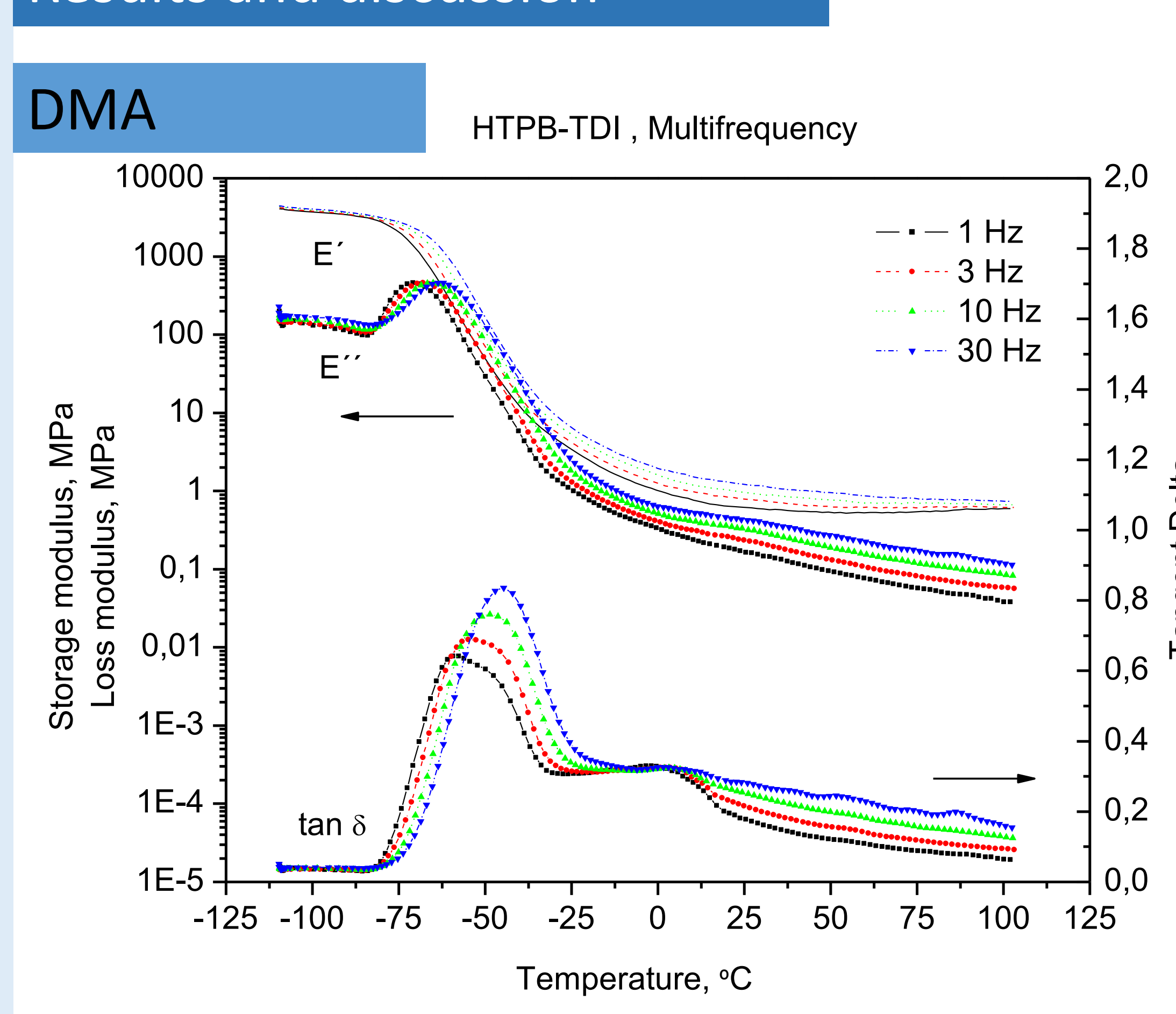

DMA analysis shows the existence of phase separation and, then two different glass transitions regions: the related to cooperative motions of the soft and hard segments, respectively. At a given family, the relaxation of soft segments takes place at similar about $-50{ }^{\circ} \mathrm{C}$ for Butacene specimens, at $1 \mathrm{~Hz}$ in $\mathrm{E}$ " basis). The storage modulus is about $1000 \mathrm{MPa}$ for all of them at the lowest temperatures.

\section{DSC}

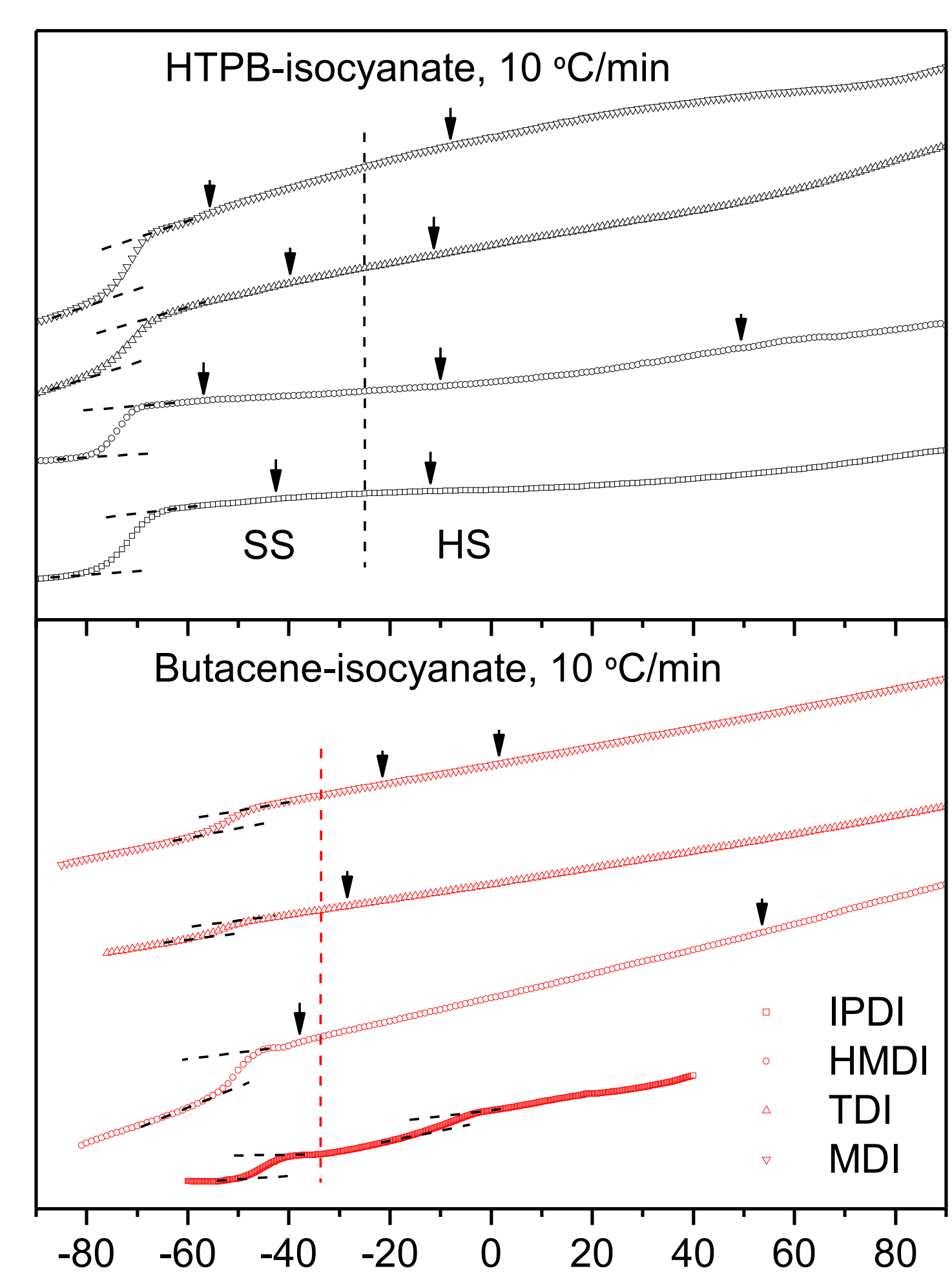

Temperature, ${ }^{\circ} \mathrm{C}$

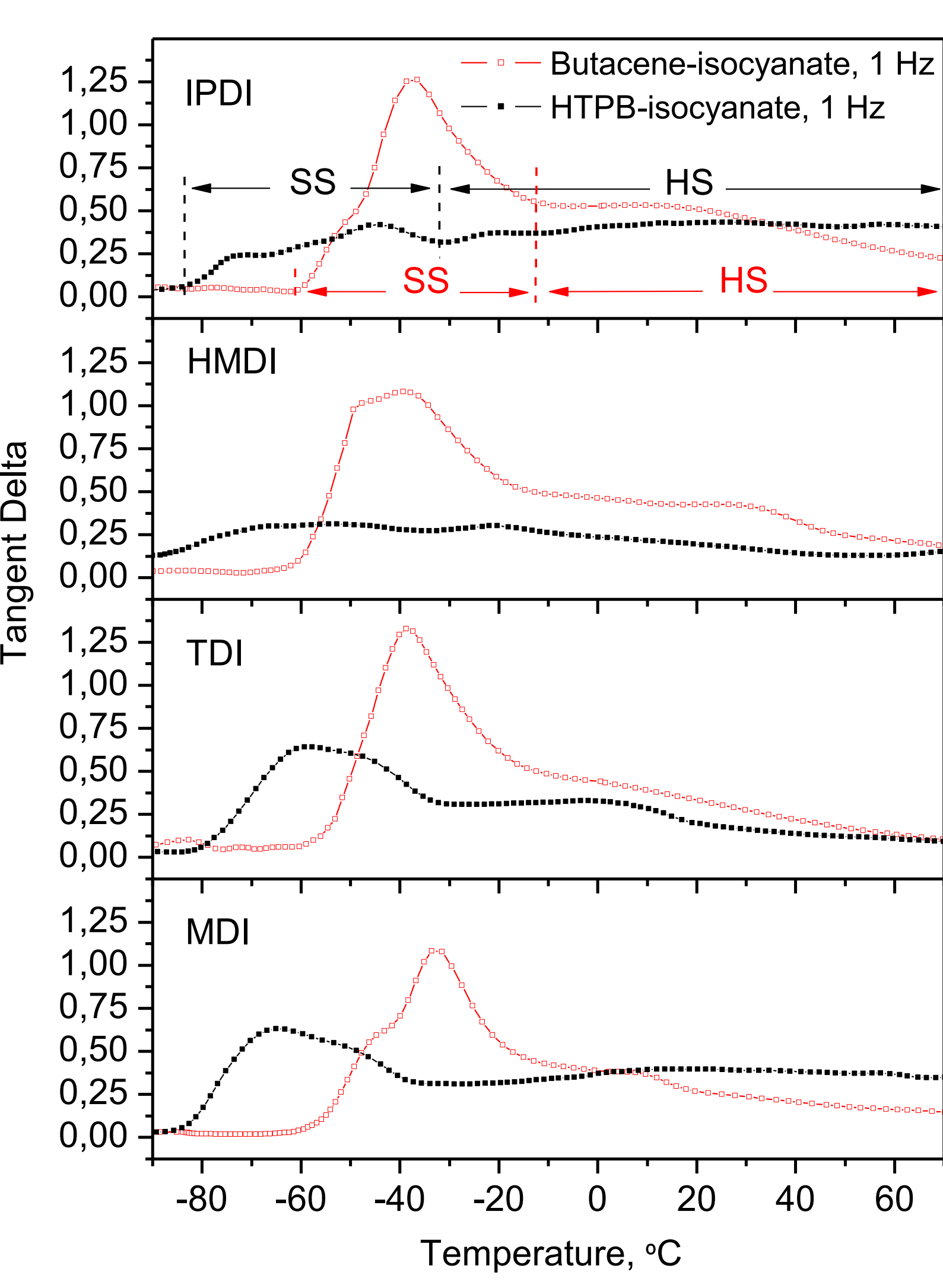

The relaxation of soft segments exhibits in the Butacene systems an intensity in $\tan \delta$ much higher than in the HTPB samples, implying a greater energy dissipation capacity at this temperature range in the former specimens. The relaxation time distributions associated with the SS mechanism and, consequently, its width, are narrower than those involved in the relaxation of the rigid segments.

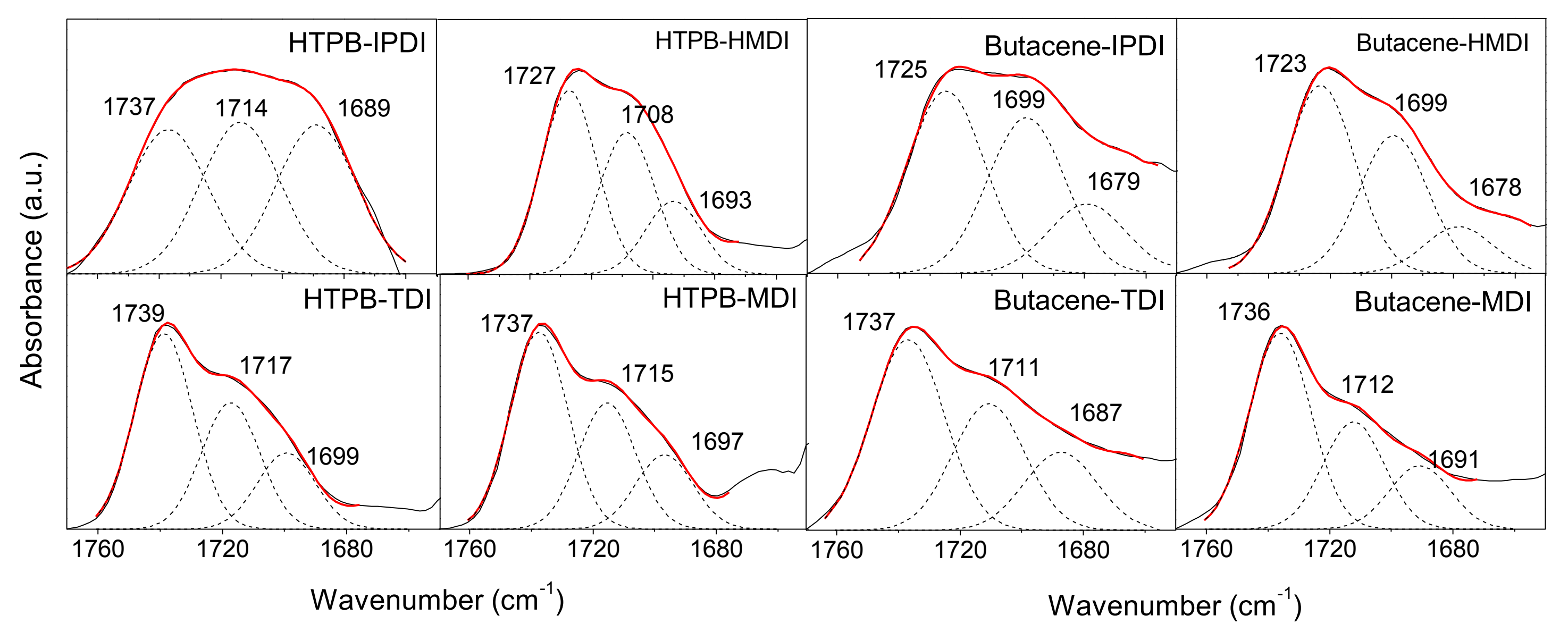

Quantitative regarding the retainformation f non-hydrogen bonded (1738$\left.1725 \mathrm{~cm}^{-1}\right)$, loosely hydrogen strongly bonded and ordered urethane hard segments (1700$\left.1680 \mathrm{~cm}^{-1}\right)$ were obtained by the deconvolution of $\mathrm{C}=\mathrm{O}$ region (A) and analysis of the relative absorbances $(B)$.

\begin{tabular}{|c|c|c|c|c|c|c|c|}
\hline & \multicolumn{3}{|c|}{ HTPB } & \multicolumn{3}{|c|}{ BUTACENE } \\
\hline \multirow{4}{*}{ |PD| } & & 1737 & 1714 & 1689 & 1725 & 1699 & 1679 \\
\hline & $\cdots$ & & & & & & 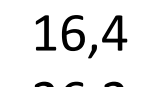 \\
\hline & B (\%) & 31,4 & 37,2 & 31,4 & 37,3 & 36,5 & 26,2 \\
\hline & $\left(\mathrm{cm}^{-1}\right)$ & 1727 & 1708 & 1693 & 1723 & 1699 & 1678 \\
\hline HMD & $\begin{array}{l}A(\%) \\
B(\%)\end{array}$ & 40,2 & $\begin{array}{l}35,6 \\
37,3\end{array}$ & 22,5 & $\begin{array}{l}50,5 \\
46,2\end{array}$ & 36,8 & 17,0 \\
\hline \multirow[b]{2}{*}{ TDI } & $\left(\mathrm{cm}^{-1}\right)$ & 1739 & 1717 & 1699 & 37 & 1711 & 1687 \\
\hline & $\begin{array}{l}\text { A (\%) } \\
\text { B (\%) }\end{array}$ & 45,4 & 33,5 & 21,1 & 44,3 & 33,5 & 22,2 \\
\hline \multirow{2}{*}{ MD } & $\left(\mathrm{cm}^{-1}\right.$ & 1737 & 1715 & 1697 & 1736 & 1712 & 1691 \\
\hline & $\begin{array}{l}A(\%) \\
\text { (\%) }\end{array}$ & $\begin{array}{l}49,7 \\
4465\end{array}$ & $\begin{array}{l}31,7 \\
327\end{array}$ & $\begin{array}{l}18,6 \\
208\end{array}$ & 513 & 307 & $\begin{array}{l}17,4 \\
180\end{array}$ \\
\hline
\end{tabular}

Deconvolution results indicate the presence of a substantial IPDI with a value close to $30 \%$ ), a reasonable amount of hydrogen bonded, disordered carbonyl (around of 35\%, except for the samples based on aromatic diisocyanates, with a value close to $30 \%$ ) and small amount of strongly hydrogen bonded carbonyl groups (around 20\% for those PU samples containing aromatic rings as hard segments, and low values more significant differency between both series is determined by the lower wavenumbers for the signals representative of well-ordered hydrogen bonded structure for the PUs based on Butacene (for PUs from HTPB $\geq 1690 \mathrm{~cm}^{-1}$ vs from Butacene $\leq 1690 \mathrm{~cm}^{-1}$ ).

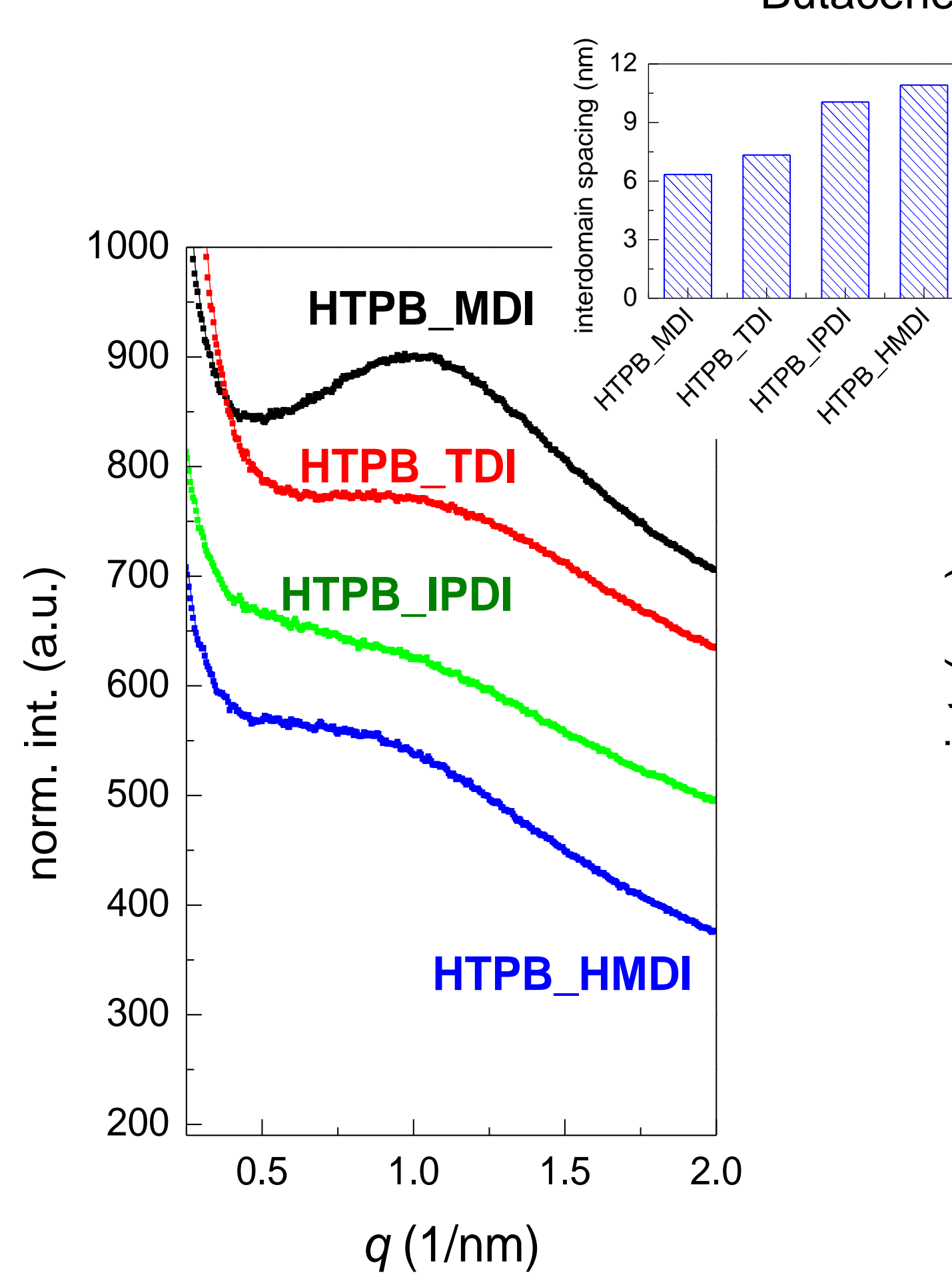

SAXS

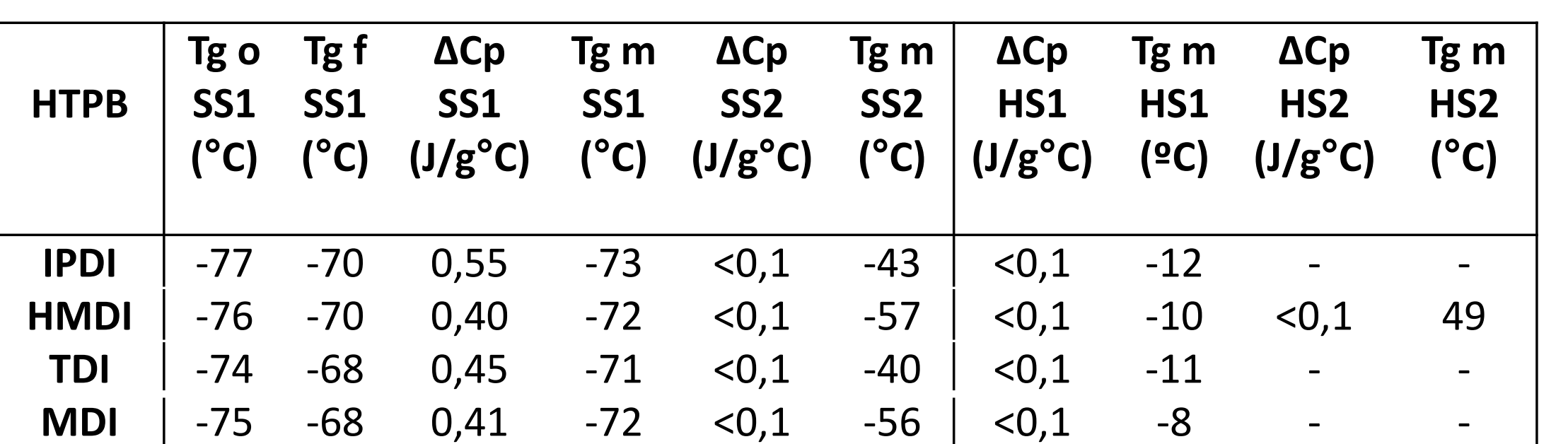

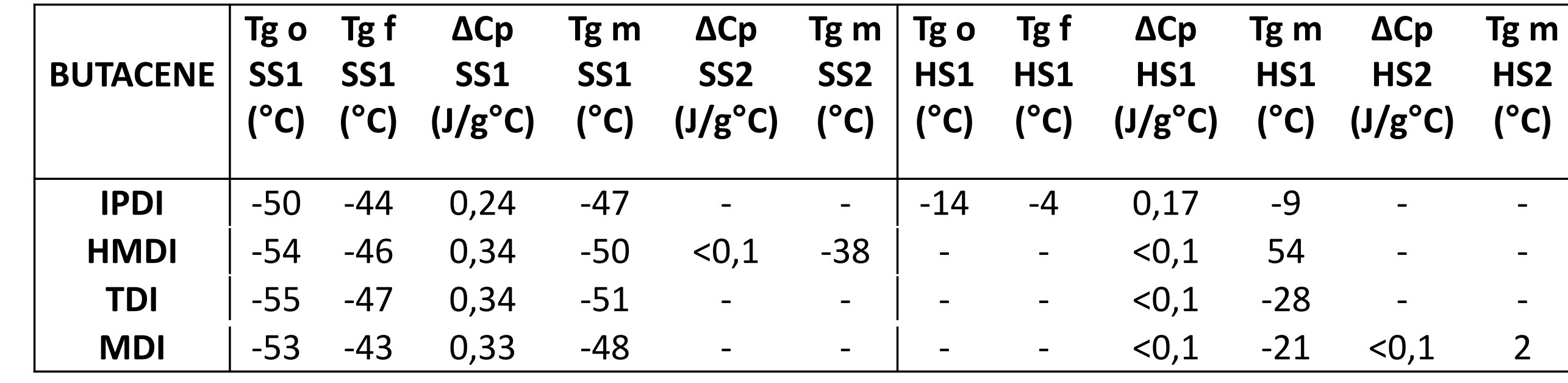

DSC results are in a good agreement with those obtained by DMA analysis. Phase separation is observed and, then, two different glass transitions regions appears: the ascribed to generalized motions of the soft and hard segments, respectively. It should be commented that only the glass be accurately determined since the one ascribed to HS involves a very small specific heat increment (lower than $0,1 \mathrm{~J} / \mathrm{g}^{\circ} \mathrm{C}$ ).
Ordering capability seems to be dependent on the lack or presence of Butacene in the macromolecular architecture. Furthermore, the mean interdomain spacing between hard domains $\left(d=2 \pi / q_{\max }\right)$ is also strongly dependent on the nature of diisocyanate, those aliphatic ones showing values higher than the spacing obtained for hard segments containing aromatic diisocyanates.

\section{Conclusions}

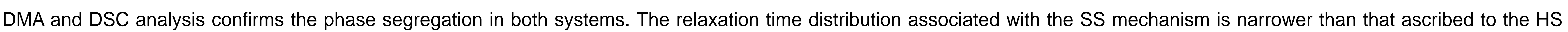
relaxation, i.e., it involves a broader temperature range.

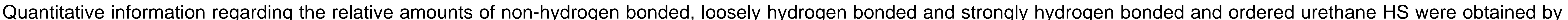

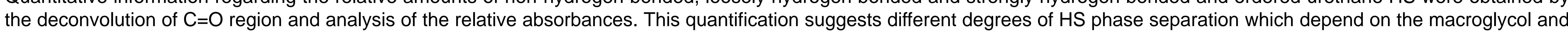
chemical structure and the symmetry of the diisocyanate

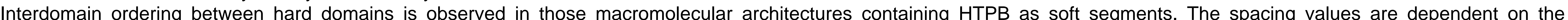
diisocyanate used. 